Judith Purkarthofer*

\title{
Children's drawings as part of School Language Profiles: Heteroglossic realities in families and schools
}

DOI 10.1515/applirev-2016-1063

\begin{abstract}
Child language development occurs in a given environment, complete with explicit and implicit regulations, intervening actors with their coherent or contradictory intentions, and specific resources for speakers. The main research question of this contribution is: What can drawings as parts of School Language Profiles tell us about the multilingual environments of bilingual families and schools? The analytical framework of spatial and language practices provides a means to talk about how and why certain expressions are chosen and which influences are mentioned in relation to school and family. In particular, the focus is on how heteroglossic spaces are constructed through local/spatial/language practices and how these constructions are represented in the drawings of children. The drawings were collected in a bilingual school in Austria, with Slovene and German as languages of instruction. Children's drawings present a fine-grained perception of their multilingual surroundings and we see how children refer to home/school in their drawings and distinguish language realities. Findings indicate that language regimes and goals of families and school are in close relation to each other, have influence on each other but do not necessarily always complement each other. This means that in analyzing heteroglossic realities, both cannot be regarded as separate (or separable) spaces.
\end{abstract}

Keywords: children's drawings, social space, multilingual school, lived language experience

\section{Introduction}

Child language development occurs in given social spaces, complete with explicit and implicit regulations, intervening actors with their contradicting intentions, and specific resources for speakers (see e.g., Norton 2013;

*Corresponding author: Judith Purkarthofer, MultiLing Center for Multilingualism in Society across the Lifespan, Universitetet i Oslo, Postboks 1102 Blindern, Oslo 0317, Norway, E-mail: judith.purkarthofer@iln.uio.no 
Kramsch 2009). Research on lived language experience (Spracherleben) aims to understand the heteroglossic lifeworlds of speakers: it takes into account the experiences that speakers have while growing up with different languages, their beliefs, values, and language ideologies which are shared in a wider community of speakers (Irvine and Gal 2000). Furthermore, it considers the situated language regime in their surroundings, consisting of explicit and implicit regulations in a given space (Kroskrity 2000). Lived language experience focuses less on language competencies and is more concerned with perceived capabilities, i. e., acting in one's everyday life with one's multilingual resources. This approach has been developed to work on multilingual language biographies and speakers' language choice with regard to media, education and family life (Busch 2006) and was further used in a variety of contexts, among them language and trauma (Busch 2016). The speaker-centered approach which is used in this analysis draws on Bakhtin's concept of heteroglossia, as it is taken up in recent studies (Busch 2012; Heller 2011) and opens the way for analyzing multidimensional language experience through biographic and ethnographic approaches.

Heteroglossia refers to a multitude of voices, languages, and discourses and it represents a notion of linguistic resources, organized in a person's linguistic repertoire (Gumperz 1964; Busch 2012) that are not artificially separated into autonomous languages. Heteroglossia rather sees languages as interactionally constructed and situationally negotiated. Heteroglossic spaces, as they are addressed in this research, are understood as social spaces where linguistic and communicative resources meet. These spaces are not only places of language use but also ascribed with symbolic value and develop over time to form their own histories. As such, they are recognizable as continua with their inherent multiplicity (Massey 2005).

In order to access the representations that children have of their social and language surroundings, children's drawings were collected in a bilingual school in Austria, with Slovene and German as languages of instruction. With this study, heteroglossic spaces reveal themselves according to the different constructions of linguistic resources that participants use: for example, teachers thinking about their languages of schooling, children imagining their future languages for holidays, and parents sticking to the 'language of social success'. The focus of this study is on the drawings of children, but these results have to be contextualized in a broader setting, where parents' motivations, teachers' actions and negotiations between them are taken into account (Purkarthofer 2016). This means that different perspectives speak to each other and that this study becomes a point of interaction for different research traditions: language 
use in the family, and more specifically family language policy have developed as specific fields of research, drawing attention to the agency of children and societal expectations and discourses (King 2016; Lanza 2007). Imaginations and aspirations of parents have been found to have great impact on transmission and language maintenance in families (i. e., Brizic 2007; Dagenais and Berron 2001). Parents show interest in the linguistic repertoires of even very young children in terms of emotional development but also in terms of social value, (imagined) employability, and future perspectives. Schools as places of multilingual encounter have been the focus of a fair amount of recent studies relevant authors from the North American and Canadian context include Hornberger (2009), García and Sylvan (2011), and Dagenais et al. (2009) and also in Europe, the topic is at the heart of several recent publications (i. e., Auger 2010; Ziegler 2013; Purkarthofer 2016).

Questions of children's lived experiences of language regimes in school and their links to familial language regimes are the main focus of this study. The research reported here, organized around sites of language use and language experience, offers a new and innovative perspective on experienced language requirements as well as strategies of children to interact with languages. Thus my research questions read as follows: How are heteroglossic spaces represented in the drawings of children through a spatial practices analytical lens? What do drawings tell us about the multilingual reality of bilingual families and schools? And finally on a methodological note, I discuss the contributions of the study to visual data analysis in multilingualism research.

\section{Sites of language use and negotiation - Situated spatial practices}

Connections between local, spatial and language practices might not be obvious at first sight, since language is often studied through de-spacialized texts and recordings. Understanding language practices as dynamic and situated practices (i. e., Canagarajah 2013; Gee 2004; Pennycook 2010) offers explanations for negotiations of language and power and social discourses influencing speakers and communities, and insights into lived language experience.

For a long time space was only used as an everyday life category in linguistics and educational studies, while theoretical discussions on the conception of social space were present in philosophy, sociology, and human geography (i. e., Tuan 
1977; Massey 1994; Rose 1999). In the British tradition of critical human geography, Doreen Massey and Gillian Rose added to the body of knowledge with their critical studies of space and spatial practices, linked to feminist studies and thinking about the place and space of women in society. Yi-Fu Tuan, who applied the concept of experience to the relations of humans to and in space, highlights the power of ethnographic approaches. These notions of experience and the creation of meaning through expression is closely linked to the notion of lived language experience talking about the emotional, motivational, and social aspects of language use. As Tuan writes: "Experience is directed to the external world. Seeing and thinking clearly reach out beyond the self. [...] What can be known is a reality that is a construct of experience, a creation of feeling and thought” (1977: 9). Thus, thinking and talking about space and language requires thinking about our experience of spaces and languages.

The French philosopher and sociologist Henri Lefebvre created a theoretical framework on social space that provides categories which help to address the questions I would like to answer in this article. Lefebvre saw social space as a complex phenomenon, comprised of products as well as processes. He presents a concept of a triadic production of space - executed by social actors and societies. The production of space is done over time, through a myriad of actions, some of them very distinct and visible, some (or most) as part of the almost-unnoticed everyday life. Lefebvre distinguishes between three main aspects of production:

(1) Spatial practices which are seen as a set of social practices that produce space, "slowly and surely as it masters and appropriates it" (Lefebvre 1991: 38). During the conducting of research (and hence, obviously also to the participants) these practices are hardly ever explicit or conscious, but they form a kind of continuity that over time, makes space recognizable as such. While one can (and indeed continuously does) participate in spatial practices, these are very hard to grasp in the form of direct data as every form of re-telling produces representations instead of practices.

(2) Spatial representations are linked to the concepts of a certain space; what is planned and conceived, and also to the intended rules or norms valid in social space. Ideas about the use of languages in a specific space (i. e., as languages of instruction) can be seen as spatial representations.

(3) The third aspect, spaces of representation, consist of commentaries on lived space as it is created and used by actors. Spaces of representation are what Lefebvre names perceived spaces, the spaces of inhabitants and users 
(i. e., the un-intended use of libraries as a secret hide-out). "This is the dominated - and hence passively experienced - space which the imagination seeks to change and appropriate. It overlays physical space, making symbolic use of its objects" (Lefebvre 1991: 39).

I use Lefebvre's theory as a framework to understand the practices and activities in school and to understand how language use and learning is done by the participants of a school. Linking spaces of representation to lived experience gives insights into the negotiations of language use and their spatial components. These relations are never clear-cut, but become interpretable as we are able to look at how "production process and product present themselves as two inseparable aspects, not as two separable ideas" (Lefebvre 1991: 37). Lefebvre speaks about the connections that humans establish to socials spaces and he stresses the active participation to produce these spaces continuously: "Human beings' do not stand before, or amidst, social space; they do not relate to the space of society as they might to a picture, a show, or a mirror. They know that they have a space and that they are in this space. [...] they act and situate themselves in space as active participants" (Lefebvre 1991: 294).

The production of space has not been linked to the distribution of languages nor to the experience of speakers within their environment, and only in the last few years has space been invoked as a concept in language studies (Pennycook 2010; Gee 2004). Lefevbre's contribution to recent discourses on spatialization and to heteroglossic spaces lies in the applicability of his model of spatial practices, spaces of representation, and representational spaces to specific language environments. The focus on the intentions of producers of space and multilingual speakers in their heteroglossic environment serves as a means to understand both formal and informal learning environments with their situated practices (Lave and Wenger 1991).

Children's perceptions of space, their environment and relationship have not been of primary concern to sociologists, educators, or linguists. The development of a sociology of childhood where children were no longer small people with unpredictable behavior and reasoning with a kind of "minority social status" (Mayall 2002: 20) only happened very recently and, inspired by feminist research, led to research designed to understand the perspectives of children. Their positioning as actors with their own agency focuses on their everyday experience of both school and family life (Lanza 2007; King 2013), recognizing that they know these spaces well, even though this knowledge may be hard to verbalize. 


\section{School Language Profiles as a means of researching in, and with school communities}

Being positioned in a speaker-centered research paradigm concerned with lived language experiences (Spracherleben), I focus on ethnographic and biographic exploration to understand child language development in multilingual settings. Inspired by Busch's (2010) School Language Profiles, which were developed in a South African context, I was able to pursue the School Language Profile (SLP) of a bilingual dual-medium primary school in the regional capital of Carinthia in Austria, a medium sized town of about 100,000 inhabitants and the educational center of the region with a diverse set of kindergartens, schools and a university. In the region around the capital city, but not in the city itself, Slovene is officially recognized as a regional minority language. The school at the time of data collection was attended by approximately 100 pupils, aged 6 to 10, who are educated through the medium of German and Slovene, with the language of instruction changing on a daily basis. All teachers are bilingual and instruction for one class is done by the same teacher in both German and Slovene. While the school traditionally catered for Slovene-speaking families, over the last years a larger part of the school population has had German as a stronger language and the school attracts a more varied student body, with languages other than German or Slovene becoming more common. The research in the school took place over a period of 18 months in 2010 and 2011 and further meetings were arranged after data collection to discuss findings and future developments.

Our SLP consist of a series of activities and research modules aimed at involving teachers, students, and parents in joint research of their language experiences (for a more complete picture see Busch 2010; Purkarthofer 2016). Verbal and multimodal activities are combined: participant observation, different interview settings and group discussions, photo elicitation tasks and linguistic landscapes, and workshops around the linguistic repertoires of students. Feedback activities and commentary from all members of the school community are built into the research process at recurring stages. Throughout all these tasks, the focus is on the speakers' biographical and situational experiences, taking into account their motivations, imaginations, and affects. For this article, I draw on a selection of data, focusing on children's drawings and their links to the wider school language profile. While the combination of data is very relevant, I am only describing one method, drawings, in greater detail and would like to point to forthcoming publications that look more 
closely at other aspects of this research. To situate the findings from the children's drawings, I provide a summary on the complementary methods used in the SLP in Table 1.

Table 1: Methods in the SLP (incl. number of persons involved).

\begin{tabular}{ll}
\hline Method & Number of persons \\
\hline Teacher interviews & 12 individual interviews \\
Parent interviews & 10 individual interviews \\
Parents group discussion & 1 group (6 adults) \\
Workshops with children (biographies) & 4 groups (40 children) \\
Workshops with children (situational drawings) & 4 groups (34 children) \\
Linguistic landscapes & 1 researcher (230 pictures from 2010 and \\
& $2011)$ \\
Linguistic landscape with children & 15 children \\
Photo elicitation (teachers) & 4 teachers \\
Participant observation & 1 researcher (11 days in a period of 18 \\
& months) \\
\hline
\end{tabular}

\subsection{Situational drawings}

Situational drawings, inspired by works of researchers in different countries, are meant to help understand the relationship of the child with her/his environment. This was used in three key pieces of research: on identity construction of minority language speakers in Finland (Pietikäinen et al. 2008), on viewing the multilingual environment of children 'through their eyes' in combination with linguistic landscapes in Canada (Dagenais et al. 2010), and on understanding relationships with school and developing identities of school children in Germany (Westphal 1997). Westphal used drawings to understand the spatial experience of young school children and showed "the interplay between the spatial constitution of the school and the spatial understanding of the children" (Westphal 1997: 24, translation of the author). As Kalaja et al. (2013) point out, speakers not only participate in discourses and use verbal language resources but they also have a history of using semiotic resources, being visible, for example, through the kinds of metaphors used to show and describe learning experiences. Children's drawings express lived experiences in social space (spaces of representation in Lefebvre's triad), and they may speak about the planned aspects of space but they cannot be read as documentary accounts of reality. 
In the course of on-going research in this dual medium primary school in Austria, six groups of children aged 8-9 years talked about their languages, their lived language experience and their perception of social spaces in workshops with the researcher. In four of these workshops, the drawings were introduced and the children were asked to draw situations where they would use their two main languages, in most cases German and Slovene. The children chose the content of their drawings and attributed titles to them. All children were informed about the research and the role of the researcher and handed in their drawings on a voluntary basis. All names in the following examples are pseudonyms. Independent from this activity, all parents had been informed about the research earlier on.

Among all drawings, family/home and school were the two contexts represented most frequently. Other contexts (i.e., holidays/travel, playing with friends) were depicted less often, as shown in Table 2. Family situations were sometimes very specific and unique (rushing to the hospital for the birth of the sibling), but more often than not they represent stylized family settings: drawings that remind the viewer of family portraits with all members aligned along an imagined line, or the family home being used as a symbol of family/at home. The verbal descriptions and explanations centered around everyday activities like saying good night, watching television, or playing in the garden. All the children use both languages on a daily basis, together with more languages as part of their family repertoire or further language learning in the school context. Three children chose family languages (other than Slovene) as part of their drawings. Ten months after the first drawings, ten children again took part in a workshop and this time, they were asked to draw school-related situations for their languages.

Table 2: Topics of situational drawings (2 drawings per child).

\begin{tabular}{lr}
\hline Topic of drawing & Number of drawings \\
\hline School & 16 \\
Family & 16 \\
Symbols (Flags, etc.) & 10 \\
Holiday /Travel & 10 \\
Friends & 8 \\
Play /Leisure & 7 \\
Fantasy & 1 \\
\hline
\end{tabular}




\section{Analysis and findings}

The analysis is centered around the drawings and the short descriptions the children gave during the workshops, which were recorded and transcribed. For the subsequent analysis, I chose drawings by four children out of a total of 68 situations drawn by 34 children. Two of the children focus on family relations (Figures 1 and 2), and their drawings show similarities between the representation of language use in the home. Two children who focus on school (Figures 3, 4 and 5) were chosen to show the development of the representation of social space and language use over time. Figures 4 and 5 were drawn in the follow-up workshop. While those drawings were chosen for illustrative purposes, the findings are supported by the larger set of drawings. Despite very individual expressions in the drawings, shared underlying regimes can be understood from their totality.

When looking at situational drawings, symbolic use is sometimes very obvious, employing commonly understood symbols like the blackboard, books, and tables to signify 'school' - but the children also use symbols that gain their significance only in combination with the verbal explanations when concrete objects become meaningful as a symbol for former activities, repeated actions, or rituals. In this sense the drawings, in combination with their accompanying stories, tell us about episodes, moments that are distinguishable from their surroundings for different reasons and can be told in a (more or less) coherent way. To get a picture of something 'Sich ein Bild machen', is thus the (conscious) action of arranging memories and available/speakable resources to form a specific picture and to talk about experience with the emerging relations between the different parts (Lange 2001: 59). Similar to biographical telling, the need to finish the story may emerge from the process (Schütze 1976: 14), and already the choice of topic or situation may indicate its relevance for the speaker.

Both means of visual analysis (Rose 2007) as well as multimodal analysis and conversational analysis of the descriptions were combined to help understand the semiotic resources used by children to explain their lived language experience. Working with Lefebvre's triadic scheme as an analytical lens, I seek to understand the connections of spatial practices, representations of space (planned aspects) and spaces of representations (lived experiences). The outcomes speak to us about the joint (though not uniform) construction of spatial, social, and language practices in families and school. 


\subsection{Heteroglossic family spaces}

To illustrate the analysis and findings, I will discuss here examples of situational drawings in detail. The children explained their drawings and the persons depicted and commented on their motivation for these specific motifs. The titles of the drawings, reproduced below the drawings, were created by the children and translated into English for this article

(a)

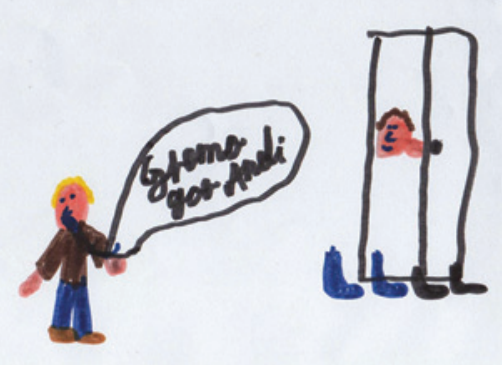

(b)

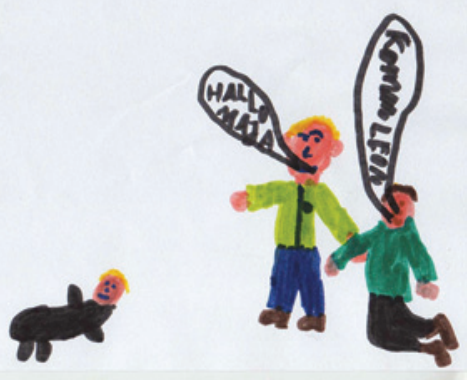

Figure 1: Leaving to see a friend (1a, Slovene) /At home (1b, German).

The drawings are typical in transcending the imagined clear-cut lines of languages, and thus linking domains of language use to past and future language practices. Figure 1 was drawn by a child from a German-speaking family and speaks about different language practices that are chosen for the two parts of this drawing: both are situated within the family home. In the drawing to the left (1a), a Slovene-language situation, the child is standing in the entrance way telling his parent that he is leaving to see a friend. He is using the Slovene phrasing in combination with the friend's name: Gremo gor Andi 'I'm going to Andi's'. This friend's family language is Slovene and thus the language use in this drawing can be regarded as leading towards this intended destination, being the anticipated language of communication in the future space. In support of this interpretation, the German-speaking parent is somewhat hidden behind a door and does not display a reaction to the announcement. Still, the setting of the family home underlines the potentiality and possibility of languages there, i. e., the openness of the family to expanding language use. 
The situation to the right (1b) involves the child, his mother, and the baby sibling: the speech balloons comprise names and greetings and a short imperative request, all in German. It reads Hallo M. 'Hello M.' and Komm L. 'L., come (here)'. According to an interview with the child's mother, the main family language is German, but the family has several friends who communicate in Slovene and can be considered part of the bilingual cultural environment. The family is represented by the persons, thus taking the family beyond the physical space of the home to potential other spaces where family members interact. The left drawing (1a) quite visibly links the family home (now in the form of a physical space, an area of passage) with the outside world, in this example with the neighbor's house and family. In this way, it seems to be situated between connected language spaces. The child himself is an active speaker in both drawings, using German and Slovene phrases as depicted in the speech balloons.

Inspired by biographical methodologies, these situational drawings are able to capture the openness of growing up in heteroglossic language spaces, while still being able to speak of the perceptions of language negotiations. Looking at Lefebvre's notions, there is little representation of rules and regulations and through the specific situation we can perceive these illustrations as accounts of the lived experience. In other words, the child demonstrates his ability to attribute specific languages to specific settings, not only to physical spaces like the family home but also related to intentions and projections (as in the very moment of leaving one language space to move towards another one).

Figure 2 also represents language practices connected to the family. This child chose Bosnian as the second language, as this is considered his family language (both by his account and by the school's). He chose a different style for the drawings and explains their belonging to a German and Bosnian speaking environment to the researcher while drawing.
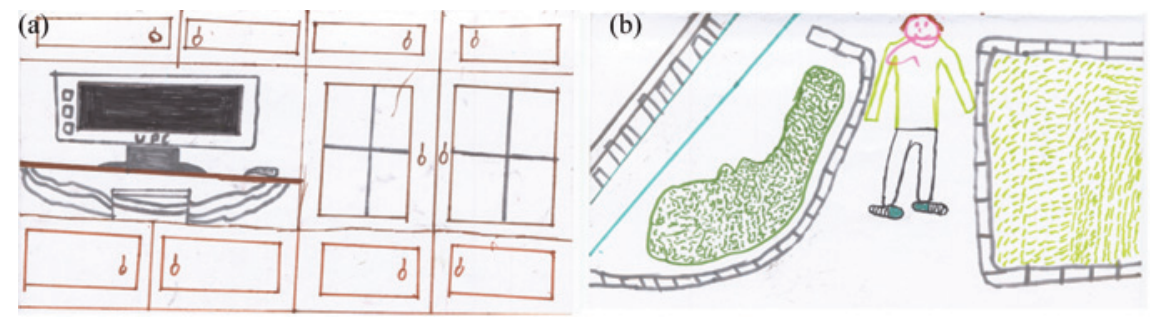

Figure 2: At home (2a, Bosnian) /With Siblings (2b, German). 
(1) (Drawing 2a) $)^{1}$

Researcher: What is your drawing about?

Mirza: My apartment, the living room. (...) It's just the living room, like this. Researcher: Which language do you speak there?

Mirza: Bosnian

(2) (Drawing 2b)

Researcher: And with whom do you speak German, normally?

Mirza: With my brothers (...), they are older and we ride bikes

As we have seen in Figure 1 as well, these drawings show the fine grain distinctions in perceived language regimes: both are situated in a family space, but different languages are considered relevant. The drawing to the left (2a) represents Bosnian as the child's family language in the living room at home, with a prominent TV set as the center piece. Stepping out of the family home, the drawing to the right (2b) is associated with the siblings of the child playing in the garden using German, the main language of the peer environment. This language shift from the parents' heritage and family language to the language of school with older siblings is reported very often in families.

One further indication of this shift might be in the representation of the child as a person in the right drawing (2b), the use of colors (against the rather monotone interior) underlining the orientation towards the outside and also the language of the environment. Both drawings are within the domain of the family and there is no comment made about the experienced heteroglossic contexts these drawings point to. Given this (non-expressed) normality, we find here further evidence that regarding language use primarily from a domain-centered perspective might fall short of grasping the heteroglossic lived realities.

Looking at both Figures 1 and 2, there are almost no pre-made symbols to be found and the representations of the family home/family settings are inspired by the individual and biographical experiences of the children. While they have been constructed by the actors, these represented everyday actions can be seen as views into the lived language experience, as the children "know that they have a space and that they are in this space” (Lefebvre 1991: 294). Both children show us their perception of language practices, being present as actors and as

\footnotetext{
1 Transcription conventions

Transcripts were translated into English by the author. Specific characters:

/Interruption, followed by reformulation

(...) Deletion of parts, Shortening

[...] Description, Comment of the author
} 
speakers (by the means of speech balloons) in at least one of their drawings. But even when speaking of the personal, the individual family home, discourses and societal evaluations play a role in the representations. While it is not explicitly mentioned in the explanations, we can understand the separation of indoor- and outdoor-languages as a reproduction of societal evaluations: the majority of the town's inhabitants will regard German as the main language of interaction and the reproduced spatial representation in (2b) points to this expectation. This becomes particularly apparent when parents talk about the fear that their children will be labeled as foreigners (as is said to happen in non-bilingual schools or in the surroundings).

Looking at the choice of method, we see that the situational drawing approach invites flexibility and allows children, despite the task of drawing different language situations, to transcend expected boundaries of language use. The family is thus not a clearly separable system with only one language regime but a nexus of interactions, linked to persons and goals. Apart from socially expected results, different and more complex interpretations and explanations can be heard and seen.

\subsection{School and its heteroglossic practices through the eyes of children}

Situational drawings of school situations are as frequent as family-related drawings. School is an important part of the everyday life of children, both socially and temporally, and given the school context of this workshop, this is easily explained. Underlining this fact, about half of the children combined a drawing from school with a drawing from the family domain. Situations in school are represented by the school building, by classroom situations, materials in use in the classroom, and drawings of the blackboard (and on this blackboard).

Examples of school drawings appear in Figures 3 and 4. This set consists of four drawings by one child, drawn with an interval of ten months between them. The first set of drawings ( $3 a$ and $3 b$ ) shows two houses, with the entrance door and the door handle as the only details. The form of the building is by no means similar to the actual school building but it shows us prototypical houses (walls, door, and red roof). Next to each building there is a human figure: in the German-language drawing (3a) the speech balloon says 'School [is] over'. The equidistant positioning indicates a balanced, though relatively distant, feeling which might also be enforced through the emptiness of the school buildings. 
(a)
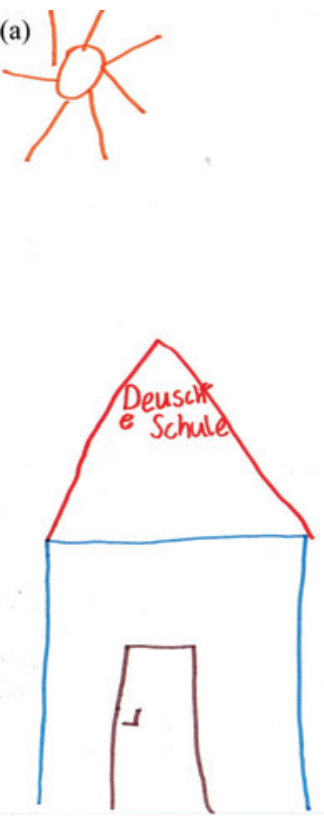

(b)

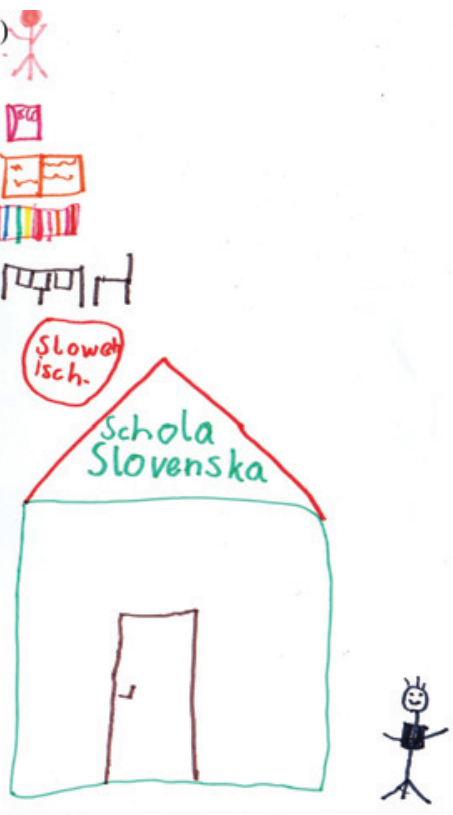

Figure 3: German school (3a, German)/Slovene school (3b, Slovene).

Both school buildings are labeled, one as 'German School' and the other as 'Slovene School'. Apart from the evident errors in the spelling on both labels, there is no labeling like this in the actual building; instead, there is only a small sign that reads Volksschule / Ljudska šola 'Primary school' next to the entrance. While I do not want to focus on the orthographic errors of the labeling, I will use this example to take a closer look at the strategies at play here: given the need to distinguish between the situations at school, the labeling seems like a feasible way. The Slovene labeling (3b) uses some of the German orthography (sch in the place of $\check{s}$ ), and is further supported by a small cloud-like sign over the roof, where 'Slovene' is written in German. Taking up some subtle clues, we find in the right drawing some school materials, whereas in the 'German' part of the drawing the school context is expanded through the sun. In combination with the speech balloon announcing the end of school, this may underline the stronger role of German outside of school and its closer link to leisure activities.

Ten months later, the same child drew two more pictures (4a and 4b), both situated again in the school context. While the two (main) languages of school are clearly separated in the earlier drawings, now they both form one building still with the prototypical forms but very visibly filled with color and sharing a 
common roof. The label reads Mohorjeva Hermagoras, which is the actual label above the school entrance. The other written elements in the left drawing (4a) are the words for school in each language, whereas German has the role of being the language of instruction and explanation in the said situation. Compared to the earlier set of drawings, the orthographic norms are now in place and no traces of German orthography in the Slovene words can be found.

(a)

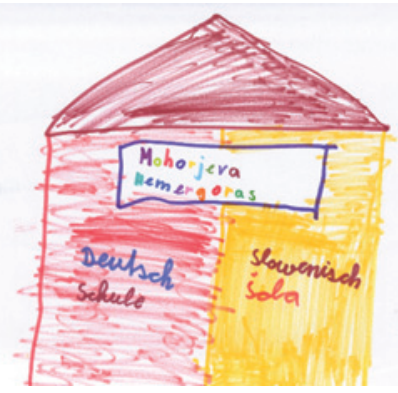

(b)

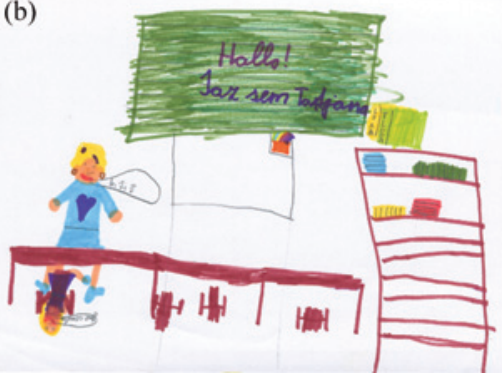

Figure 4: School (4a, German) /In class (4b, Slovene).

In the drawing on the right (4b, the Slovene-speaking situation), the child takes a new perspective and represents the classroom with her teacher and classmates. This change in perspective can be seen in most of the drawings that were done ten months after the first ones: the children's gaze seems to approach scenes more closely. Persons and situations are marked more clearly and drawn in more detail, more complex stories are told, including more direct speech through speech balloons. The dialogue between teacher and pupil in $4 \mathrm{~b}$, recited in the interaction in transcript (3) below, starts with the phrase on the blackboard and continues through the speech balloons. This modus is also seen in other drawings and seems typical in its use of space and linguistic resources but also indicates the awareness of perception and production of different modi (visual and verbal).

\section{(3) (Drawing 4b)}

Researcher: What are you doing [in the picture]?

Hannah: Well, I draw a blackboard, that is Slovene now, and there the teacher says hello, jaz sem [I am + first name] and I tell her/because she asks me kdo si ti? [who are you?] and I answer her jaz sem Hannah.

Figure 4b shows us what happens at school every day - being questioned, answering, writing on the blackboard - and it shows interaction between teacher and pupil. The situation seems very well arranged, the interaction is 
developing according to a plan and there is little doubt about the appropriateness of language use. A comparable drawing was made by the child's friend and the similarities are very obvious (see Figure 5). Iris depicts a classroom situation, with the pupils to the left, facing right, and the teacher to the right, being a little taller or more elevated than the children. School practices are at play here: raising hands to answer a question, interacting with the teacher, sitting in a specific setting: all this speaks of the spatial and social practices that are part of the language use in school. Again, this shows a very orderly environment.

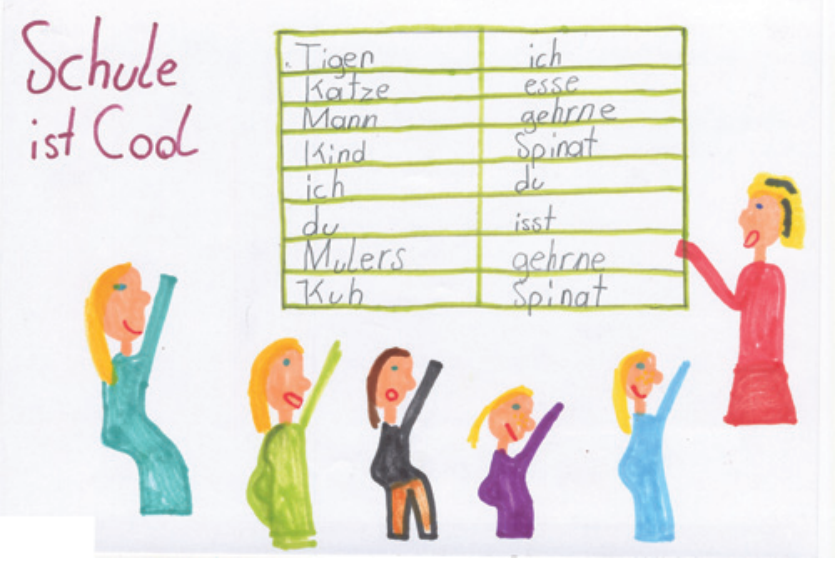

Figure 5: In class (5 German).

\section{(4) (Drawing 5)}

Researcher: You already know exactly what to draw, don't you?

Iris: Well, the classroom with the blackboard, that is then in German and then in the back I'll do the same only/on the blackboard Slovene things are written and here [in this drawing] German

The commentary (4) on Figure 5 speaks about the perceived equality of distribution of languages in the school context and the fact that one teacher teaches both of the school's languages. This child also explains very explicitly the practices involved in school.

Still, the clear depiction of language practices and seemingly uncontested language regulations is not the only layer of meaning that can be found in the drawings: in both of these classroom drawings (drawings 4b and 5), we can see 'hidden' representations that strengthen the impression of knowing about the place 
and of having appropriated one's surroundings. Hannah and Iris make use of language practices and resources that are available to them, to indicate their closeness to the represented space and to show their awareness of lived language experience. Hidden among the words on the blackboard in 5 are parts of the children's rhyme Ich und du, Müllers Kuh, Müllers Esel, der bist du ${ }^{2}$ - this 'second meaning' appears in addition to the illustrative writings on the blackboard. A similar meaning can be attributed to the folder to the right of the blackboard in drawing $4 \mathrm{~b}$ where the names of the child and of her friend are inscribed. These 'hidden' signs were not mentioned when the children talked about their drawings and only became visible as meaningful elements of the drawing after close reading and re-reading. In Lefebvre's terms, this use of symbols is attributed to the spaces of representations, the use of space by the actors present, and it adds to, and at times contradicts, the intended language regimes of social spaces.

What has to be added here is that the expected language regime of the school is not the one proposed by the school board or teachers - instead it is constructed through the expectations of children (school has to be orderly), parents (languages have to be taught), and teachers (in our school we need to have space for more than two languages) and the expected language regime seems to combine the strongest rules of all parties. At the same time, all groups of participants have opposing needs and practices, i.e., teachers seem to express less need for orderly behavior than children attribute to them.

In Figures 3 and 4, Hannah chose to draw four situations "where I speak one or the other language" situated within the school context, but linking the school context to other environments and hence speaking from within about the relations between the school and the outside. From Figures 4 and 5, along with several others from the sample, the observation of Gutiérrez et al. (2012: 143) seems valid for the given data: "Our analysis of third spaces has shown that learning contexts are immanently hybrid, that is, polycontextual, multivoiced, and multiscripted. Thus, conflict, tension, and diversity are intrinsic to learning spaces”. Even if the classification of situational drawings can be made along the lines of buildings, materials, and people present (and is closely linked to spatial representations), the explanations and - at a second look - also the drawings speak of the hybridity of language experience in a heteroglossic context (and are thus more closely linked to spaces of representation). Conflict, tension, and diversity are present in the drawings, along with word-play, hidden messages for a clearly addressed in-group of peers and expressions of possibilities that transcend the borders of the school community. I will elaborate on this in the following conclusion.

2 The rhyme literally translates: 'Me and you, miller's cow, the miller's donkey that is you' and is used as a counting rhyme similar to 'Eeny, meeny, miny, moe'. 


\section{Conclusions}

This contribution aims to answer the question how language practices are represented in the drawings of children: the main question is thus what the drawings tell us about the multilingual reality of bilingual schools and multilingual students. If we look at the drawings, we see that through the eyes (and explanations) of the children, neither families nor schools are spaces of uniform language regimes, even if language regulations and less regulated spaces are found. One of the main findings lies in the fact that we see different spaces at the same time. This multiplicity that Massey describes in her work (2005) is expressed better in drawing than in verbal narratives. This may be due to a more child-appropriate form that allows children to pick their storyline and tell their idea, without attempting to fill a perceived grown-up way of answering questions. To learn about multilingual schooling and its meaning for children (along with other relevant actors, like teachers and parents), we need to ask for lived language experience to understand what is considered relevant in everyday life. Planned aspects as spatial representations (such as models of instructions in schools and intended family language policies) are not the only factors relevant for language experience and the spaces of representation: the lived spaces and appropriations of space by speakers form a very important perspective as well.

\subsection{Heteroglossic realities in families and schools}

As was shown in Figures 1 and 2, the drawings point to family practices and language policies which are in dialogue with the school's language regimes: both cannot be regarded as separated (or separable) spaces and clear distributions between school and family languages cannot be found. The examples from two children demonstrate the complex composition of heteroglossic family life and point to potential moments of negotiation: parents may react differently to their children's multilingual language use and school might evaluate certain practices more favorably than others. Further research and in particular connections between data collected with children and also parents and teachers (as was done in the larger research project) shows aligning and diverging views (Purkarthofer 2016). Teachers, parents and children cannot be expected to complement each other in following the same language regimes and the same goals. To understand the influences and developments, both coherent and incoherent elements have to be taken into account to represent the multiplicity of social space (Massey 2005). The linguistic practices of the family home (Figure 1), where the language of the friend's family establishes ties and is 
used in anticipation of the upcoming encounter, speak to multiplicities of language use and perception thereof. In the second heteroglossic family situation (Figure 2), we see the continuity of the family members moving between home languages (the family language in the living room and German in the garden outside) and thus demonstrating multiple languages of interaction.

Looking at the drawings about the school (Figures 3-5), we are presented with a relatively balanced account of languages. Domains of language use can be seen but the practices the children talk about are quite varied and cannot be easily anticipated. This speaks for the success of the school in transmitting languages as resources and presenting children with a variety of contexts where the languages can be used. Children describe heteroglossic spaces not as separate positions but represent themselves between different language regimes and social encounters.

In the school context, languages are seen as approachable, integrating both (and even more) languages in a child's life, as it can be seen in the development over time of the drawings of the school building. The first set of situational drawings $(3 a / 3 b)$ show the expected language regime of the school, having two languages, separated in different houses or at least separated within the same house (4a). The moment that actors enter the scene these clear-cut separations are no longer possible. Still, the classroom scenes tell us about the intended practices: the asking and talking, the neat writing etc. but these neat ways are challenged through the heteroglossic and much less orderly reality. Knowing where to hide linguistic resources and where to present them to the involved reader is a clear sign of conscious commentary and of a subversive potential in the intended rules (4b and 5).

On the other hand, the school's languages are negotiated at every point: when pupils use creative methods to describe their experiences (which might differ significantly from the 'normal' and expected case), when parents expect different roles from the school, and when teachers intervene to strengthen unexpected language choices. Then, "Representational spaces [...] need obey no rules of consistency or cohesiveness. Redolent with imaginary and symbolic elements, they have their source in history - in the history of a people as well as in the history of each individual belonging to that people" (Lefebvre 1991: 41). Through the representational spaces, school is actively constructed, and learning and language appropriation can develop in response to needs in place, to local language regimes and the multilingual lifeworlds of speakers.

\subsection{Children's drawings as part of School Language Profiles}

Finally, the question is what contribution the study makes to visual data analysis in multilingualism research. Children in their drawings present a fine- 
grained perception of their multilingual surroundings, which gives us a way to see how children refer to home/school in their drawings and distinguish realities. The drawings, even more than the verbal narratives, point to the multilayered perception of reality: visual means are used for more obvious descriptions and less obvious commentary. When children present their everyday life as one driven by a set of classroom rules (the position of the teacher, ... ), they at the same time point to exceptions of that rule and they do so by employing spaces of representation, bringing in lived experience. By referencing both rules and less regulated spaces, they demonstrate precise knowledge about their environment. Speaking to administrators and educators, the children's knowledge points to relevant elements of schooling.

Visual methods allow the formulation of what is otherwise often taken for granted. While in the narratives, the assumption is 'you know how school works', the drawings tell expected and unexpected stories about how school works. These methods make obvious what can otherwise be less verbalized: through the specific time frame of drawing (uninterruptedly) and then speaking about the drawing, children focus on the topic in question (i.e., languages in school) and thus, the drawing can be used as a form of notes. By describing and interpreting the drawing, the children bundle their experiences and put them into a more comprehensive format. Where direct questions on language use might be considered complicated and rather frightening, the drawing gives authority to its author.

Language is always used in social spaces and with speakers - and sometimes we need spaces, where languages can be tried out with teachers in a dialogic setting, while at other times we have to have regulated language input to organize classroom activities. Through the combination of regulated and less regulated spaces, pupils (and parents and teachers) will find themselves in different roles, thus being less prone to stigmatization. Students can develop a sense of closeness to languages that is fostered by a diversity of experiences, and explore language use in interaction with teachers as multilingual role models. The diversity of language experiences that is expressed by the children can be read as this school's success in transmitting means of appropriation of languages as well as spaces. The symbolic resources the children use to represent their different roles and different means to express themselves help us to understand the intentions and perceptions of intended regimes which in turn can be adjusted to meet the needs of all members of the school community. If we look at material from the larger project, the negotiation of social spaces and of language practices incorporated in these social spaces brings parents, teachers and students together and makes them builders of their school's language regimes. Understanding the different perspectives through adequate 
methodology and multimodal tools leads to the analytical conclusions which allow us to link this empirical data to the theoretical frame of Lefebvre's production of space. When looking at the results from the material, I found Lefebvre's triad composed of a complex set of building blocks. There was not one group of actors that would be responsible for only one form of contribution (like rules of language use, intentions or appropriation and change) - instead, different perspectives translated into a contribution to different parts. Looking at the representations of spaces, linked to intentions and conceptions, we can see language planning: space is regulated, through policies such as school documents and linguistic landscapes, through the intentions of teachers, through the parents' expectations, but also through the re-enforcement or reproduction of rules by pupils, when they describe how school is 'normally' done.

The analytical framework of spatial and language practices provides means to talk about how and why certain expressions are chosen and which influences are mentioned in relation to school and family. The use of representational spaces (the lived) and spatial representations (the planned) allow us to distinguish who speaks about what with which goal, incorporating children's voices but also voices they bring into their drawings as citations and reported speech of teachers and fellow students. The interpretations are reached within the theoretical framework in combination with the children's interpretations - in that sense, the visuals are used as one way to talk and give confidence to children in a research setting with an adult researcher. The main advantage lies in the combination of methods with others, both visual and verbal, to cater to research participants with different needs and researchers with different questions.

\section{References}

Auger, Nathalie. 2010. Elèves nouvellement arrivés en France: Réalités et perspectives pratiques en classe. Paris: Éd. des Archives contemporaines.

Brizic, Katharina. 2007. Das geheime Leben der Sprachen. Gesprochene und verschwiegene Sprachen und ihr Einfluss auf den Spracherwerb in der Migration. Münster: Waxmann.

Busch, Brigitta. 2006. Language biographies - approaches to multilingualism in education and linguistic research. In Brigitta Busch, Aziza Jardine \& Angelika Tjoutuku (eds.), Language biographies for multilingual learning, 5-18. Cape Town, ZA: PRAESA (Project for the Study of Alternative Education in South Africa, University of Cape Town).

Busch, Brigitta. 2010. School language profiles: Valorizing linguistic resources in heteroglossic situations in South Africa. Language and Education 24(4). 283-294.

Busch, Brigitta. 2012. The linguistic repertoire revisited. In Tim McNamara (ed.). Poststructuralist challenges for applied linguistics. [Special Issue]. Applied Linguistics 33(5). 503-523. 
Busch, Brigitta. 2016. Heteroglossia of survival: To have one's voice heard, to develop a voice worth hearing. Working Papers in Urban Language \& Literacies, 188.

Canagarajah, Suresh. 2013. Agency and power in intercultural communication: Negotiating English in translocal spaces. Language and Intercultural Communication 13(2). 202-224.

Dagenais, Diane \& Catherine Berron. 2001. Promoting multilingualism through French immersion and language maintenance in three immigrant families. Language, Culture and Curriculum 14(2). 142-155.

Dagenais, Diane, Danièle Moore \& Cécile Sabatier. 2009. Negotiating teacher-researcher collaboration in immersion education. In Jennifer Miller, Alex Kostogriz \& Margaret Gearon (eds.), Culturally and linguistically diverse classrooms: New dilemmas for teachers, 234-251. Bristol: Multilingual Matters.

Dagenais, Diane, Danièle Moore, Cécile Sabatier, Patricia Lamarre \& Françoise Armand. 2010. Linguistic landscape and language awareness. In Elana Shohamy \& Durk Gorter (eds.), Linguistic landscape: Expanding the scenery, 253-269. London \& New York: Routledge.

García, Ofelia \& Claire E. Sylvan. 2011. Pedagogies and practices in multilingual classrooms: Singularities in pluralities. The Modern Language Journal 95(3). 385-400.

Gee, James Paul. 2004. What video games have to teach us about learning and literacy. New York: Palgrave Macmillan.

Gumperz, John J. 1964. Linguistic and social interaction in two communities. American Anthropologist 66/6(2). 137-153.

Gutiérrez, Kris D., Patricia Badequano-López \& Carlos Tejeda. 2012. Rethinking diversity. Hybridity and hybrid language practices in the third space. In Nancy H. Hornberger (ed.), Educational linguistics. Critical concepts in linguistics, 142-162. London \& New York: Routledge.

Heller, Monica. 2011. Paths to post-nationalism. A critical ethnography of language and identity. New York: Oxford University Press.

Hornberger, Nancy H. 2009. Multilingual education policy and practice: Ten certainties (grounded in indigenous experience). Language Teaching 42. 197-211.

Irvine, Judith T. \& Susan Gal. 2000. Language ideology and linguistic differentiation. In Paul V. Kroskrity (ed.), Regimes of language. Ideologies, politics, and identities, 35-83. Santa Fe, NM: School of American Research Press.

Kalaja, Paula, Hannele Dufva \& Riikka Alanen. 2013. Experimenting with visual narratives. In Gary Barkhuizen (ed.), Narratives in applied linguistics, 105-131. Cambridge: Cambridge University Press.

King, Kendall A. 2013. A tale of three sisters: Language learning and linguistic identity in a transnational family. [Thematic issue edited by Doris S. Warriner \& Leisy T. Wyman]. International Multilingual Research Journal 7. 49-65.

King, Kendall A. 2016. Language policy, multilingual encounters, and transnational families. Journal of Multilingual and Multicultural Development 37(7). 726-733. DOI: 10.1080/ 01434632.2015.1127927

Kramsch, Claire. 2009. The multilingual subject. Oxford \& New York: Oxford University Press.

Kroskrity, Paul V. 2000. Regimes of language. Ideologies, politics, and identities. Santa Fe, NM: School of American Research Press.

Lange, Bettina. 2001. Narrative Strukturen in (Kinder-)Geschichten und eine Analyse ihrer formalen Kennzeichen. In Hans Dieter Erlinger (ed.), Kinder und ihr Symbolverständnis: Theorien - Geschichten - Bilder, 55-156. München: KoPäd Verlag. 
Lanza, Elizabeth. 2007. Multilingualism in the family. In Peter Auer \& Li Wei (eds.), Handbook of multilingualism and multilingual communication, 45-67. Berlin: Mouton de Gruyter.

Lave, Jean \& Etienne Wenger. 1991. Situated learning. Legitimate peripheral participation. New York: Cambridge University Press.

Lefebvre, Henri. 1991. The production of space. Malden, MA \& Oxford: Blackwell.

Massey, Doreen. 1994. Space, place and gender. Cambridge: Polity Press.

Massey, Doreen. 2005. For space. London: Sage.

Mayall, Berry. 2002. Towards a sociology of childhood. Thinking from children's lives. Buckingham \& Philadelphia, PA: Open University Press.

Norton, Bonny. 2013. Identity and language learning. Extending the conversation, $2^{\text {nd }}$ edn. Bristol, Buffalo, NY \& Toronto: Multilingual Matters.

Pennycook, Alastair. 2010. Language as a local practice. London \& New York: Routledge.

Pietikäinen, Sari, Riikka Alanen, Hannele Dufva, Paula Kalaja, Sirpa Leppänen \& Anne Pitkänen-Huhta. 2008. Languaging in Ultima Thule: Multilingualism in the life of a Sami boy. International Journal of Multilingualism 5(2). 79-99.

Purkarthofer, Judith. 2016. Sprachort Schule. Zur Konstruktion von mehrsprachigen sozialen Räumen und Praktiken in einer zweisprachigen Volksschule. Klagenfurt: Drava.

Rose, Gillian. 1999. Performing space. In Doreen Massey, John Allen \& Philip Sarre (eds.), Human geography today, 247-259. Cambridge: Polity Press.

Rose, Gillian. 2007. Visual Methodologies. An introduction to the interpretation of visual materials. London, Thousand Oaks CA, New Delhi \& Singapore: Sage.

Schütze, Fritz. 1976. Zur soziologischen und linguistischen Analyse von Erzählungen. In Günter Dux (ed.), Internationales Jahrbuch für Wissens- und Religionssoziologie, 7-41. Freiburg: Westdeutscher Verlag.

Tuan, Yi-Fu. 1977. Space and place. The perspective of experience. Minneapolis, MN: University of Minnesota Press.

Westphal, Kristin. 1997. Zwischen Himmel und Erde. Annäherung an eine kulturpädagogische Theorie des Raumerlebens. Frankfurt/Main, Berlin, Bern, New York, Paris \& Wien: Peter Lang.

Ziegler, Gudrun. 2013. Multilingualism and the language education landscape: Challenges for teacher training in Europe. Multilingual Education 3.1. DOI: 10.1186/2191-5059-3-1

\section{Bionote}

\section{Judith Purkarthofer}

Judith Purkarthofer works as a post-doctoral research fellow at the Center for Multilingualism in Society across the Lifespan (University of Oslo, Norway). She received her PhD from the University of Vienna (Austria) in 2014 and has published on multilingual speakers, teacher education, school language profiles and Community Media. She is currently most interested in language and the construction of multilingual social spaces and does ethnographic and biographic research in families, schools and kindergartens. 